\title{
Petrographically quantifying the damage to field and lab-cast mortars subject to freeze- thaw cycles and deicer application
}

\author{
Chunyu Qiao ${ }^{1 *}$ (D), Nima Hosseinzadeh², Prannoy Suraneni², Sihang Wei ${ }^{3}$ and David Rothstein ${ }^{1}$
}

\begin{abstract}
Although calcium oxychloride (Ca-Oxy) is known to damage cementitious materials exposed to calcium chloride $\left(\mathrm{CaCl}_{2}\right)$ deicers, there is little direct observation of Ca-Oxy in the field due to its instability. This paper uses optical microscopy $(\mathrm{OM})$ and scanning electron microscopy coupled with energy dispersive X-ray spectrometry (SEM-EDX) to detect the formed Ca-Oxy and quantify its associated damage in a field mortar subject to freeze-thaw cycles and deicer application. The characterized damage in the field mortar is compared to that in lab-cast portland cement paste and mortar which are submerged in a $\mathrm{CaCl}_{2}$ solution of $25 \mathrm{wt} . \%$ under freeze-thaw cycles $\left(-8\right.$ to $\left.25^{\circ} \mathrm{C}\right)$. The field and lab-cast mortars show similar cracking patterns that are parallel to the exposure surface with a variation of $30-45^{\circ}$ in the preferred orientation due to the constraints of sand particles. During each lab-controlled freeze-thaw cycle, the high $\mathrm{CaCl}_{2}$ concentration of $25 \mathrm{wt} . \%$ stabilizes the formed Ca-Oxy, which continually damages the mortar and eventually results in 3-4 times higher crack density compared to that in the field mortar. SEM-EDX analysis confirms the presence of secondary deposits including Friedel's salt, ettringite and Ca-Oxy. Image analysis on thin section photomicrographs shows a reduction of $86.4 \%$ in calcium hydroxide $\left(\mathrm{Ca}(\mathrm{OH})_{2}\right)$ content in the damaged field mortar compared to the undamaged field mortar, suggesting significant leaching of $\mathrm{Ca}(\mathrm{OH})_{2}$ to form Ca-Oxy due to the deicer application.
\end{abstract}

Keywords: Concrete petrography, Substrate mortar, Calcium oxychloride, Freeze-thaw cycles, Deicers

\section{Introduction}

Chloride-based inorganic salts, such as sodium chloride $(\mathrm{NaCl})$, magnesium chloride $\left(\mathrm{MgCl}_{2}\right)$ and calcium chloride $\left(\mathrm{CaCl}_{2}\right)$, are the most commonly used deicing agents on concrete pavements in cold regions for melting snow and ice [1-4]. However, chloride ions from deicing salts can infiltrate or diffuse into the concrete, which accelerates the corrosion of the steel reinforcement and diminishes the service life of concrete pavements [5, 6]. $\mathrm{MgCl}_{2}$ and $\mathrm{CaCl}_{2}$ can also react with hydration products to form secondary phases such as brucite $\left(\mathrm{Mg}(\mathrm{OH})_{2}\right)$, magnesium-silicate hydrate (M-S-H) and calcium

\footnotetext{
* Correspondence: joe@drpcinc.com

${ }^{1}$ DRP, A Twining Company, Boulder, CO 80301, USA

Full list of author information is available at the end of the article
}

oxychloride (Ca-Oxy), which can damage cementitious materials through multiple reactions [7-9]:

$$
\begin{aligned}
& \mathrm{Ca}(\mathrm{OH})_{2}(\mathrm{~s})+\mathrm{MgCl}_{2}(\mathrm{aq}) \\
& \quad=\mathrm{Mg}(\mathrm{OH})_{2}(\mathrm{~s})+\mathrm{CaCl}_{2}(\mathrm{aq}) \\
& \mathrm{C}-\mathrm{S}-\mathrm{H}(\mathrm{s})+\mathrm{MgCl}_{2}(\mathrm{aq}) \rightarrow \mathrm{M}-\mathrm{S}-\mathrm{H}(\mathrm{s}) \\
& \quad+\mathrm{CaCl}_{2}(\mathrm{aq}) \\
& 3 \mathrm{Ca}(\mathrm{OH})_{2}(\mathrm{~s})+\mathrm{CaCl}_{2}(\mathrm{aq}) \\
& \quad+12 \mathrm{H}_{2} \mathrm{O}(\mathrm{aq}) \rightleftharpoons 3 \mathrm{CaO}^{-C_{a C l}} \cdot 15 \mathrm{H}_{2} \mathrm{O}(\mathrm{s})
\end{aligned}
$$

The reactions associated with $\mathrm{MgCl}_{2}$ in Eqs. 1 and 2 generally occur at the exposure surface since the formation of insoluble brucite blocks the pathway for further ingress $[7,10,11]$. The pore-blocking phenomenon leads to substantially lower chloride penetration depth in

\section{Springer Open}

(๑) The Author(s). 2021 Open Access This article is licensed under a Creative Commons Attribution 4.0 International License, which permits use, sharing, adaptation, distribution and reproduction in any medium or format, as long as you give appropriate credit to the original author(s) and the source, provide a link to the Creative Commons licence, and indicate if changes were made. The images or other third party material in this article are included in the article's Creative Commons licence, unless indicated otherwise in a credit line to the material. If material is not included in the article's Creative Commons licence and your intended use is not permitted by statutory regulation or exceeds the permitted use, you will need to obtain permission directly from the copyright holder. To view a copy of this licence, visit http://creativecommons.org/licenses/by/4.0/. 
concrete exposed to $\mathrm{MgCl}_{2}$ solutions compared to that exposed to $\mathrm{NaCl}$ solutions [12].

The formation of Ca-Oxy shown in Eq. 3 is expansive [13], which leads to a buildup of internal stress and damage from cracking and microcracking, especially in cold temperatures [8]. Pioneering research on the damage to concrete due to $\mathrm{Ca}-\mathrm{Oxy}$ formation dates back to the 1970s [13], and this topic was discussed in some detail in two recent review papers [14, 15]. However, very few studies have clearly shown Ca-Oxy crystals formed in field concrete; this is likely due to its thermodynamic instability and its tendency to break down during the carbonation process [16]. The $\mathrm{Ca}(\mathrm{OH})_{2}-\mathrm{CaCl}_{2}-\mathrm{H}_{2} \mathrm{O}$ phase diagram illustrates the reversible nature of $\mathrm{Ca}$ Oxy formation $[13,17]$. Because Ca-Oxy is prone to decompose as the temperature increases, it is extremely difficult to preserve $\mathrm{Ca}-\mathrm{Oxy}$ in cores or other samples of field concrete after winter or after they are removed from cold environments. Peterson et al. [16] hypothesized a decomposition path from $\mathrm{Ca}-\mathrm{Oxy}$ to calcite to explain the lack of convincing field evidence of $\mathrm{Ca}-\mathrm{Oxy}$ associated damage in pavements exposed to significant deicers.

In this work, we provide further insights into $\mathrm{Ca}-\mathrm{Oxy}$ associated damage in field and lab specimens using microscopic methods. As a concrete petrography method, fluorescence microscopy (FM) has been implemented to quantify damage over the last three decades $[18,19]$. Reliable crack quantification by FM depends heavily on two aspects: (a) the fluorescent dye should be uniformly and thoroughly introduced and dispersed along all cracks and microcracks; and (b) the fluorescent dye should only be retained in cracks and microcracks on the examined surface [19]. The first aspect is realized by proper impregnation of florescent dye in resin or organic solute such as ethanol [18]. The second aspect is assured by proper polishing after impregnation [19]. Multiple algorithms and tools have been applied for quantitative crack analysis after obtaining the images [19-21], however, little research has focused on performing crack detection and quantification using welldeveloped tools such as ImageJ that have been widely used for biological and medical research [22].

In addition to contrast enhancement for crack detection, FM shows the potential to illustrate the capillary porosity in the cement paste matrix of concrete [23, 24]. One important application is to determine water to cement ratio $(\mathrm{w} / \mathrm{c})$ [24]. More generally, the sensitivity of fluorescent light intensity to capillary porosity makes it an indicator of the microstructural alteration along the depth of cementitious materials subject to chemical attacks such as microbially induced corrosion [25].

Optical microscopy (OM) and scanning electron microscopy (SEM) are also powerful tools to discover changes in chemistry and mineralogy when cementitious materials are exposed to chemically deleterious environments [23]. For instance, OM and SEM have been commonly used to diagnose alkali-silica reaction (ASR) in concrete, and to characterize the mineral component of reactive aggregate and the chemical composition of ASR gel $[26,27]$.

This paper uses OM and FM to detect cracking and microstructural mineralogical alteration in field and labcast cementitious mortars due to freeze-thaw cycles and deicer application. ImageJ is used to quantify cracks/ microcracks in the field mortar and compare cracking to that in the lab-cast mortar and paste. SEM coupled with energy dispersive X-ray spectrometry (SEM-EDX) is used to characterize the morphology of secondary deposits and analyze their elemental compositions in the damaged field and lab-cast mortars. Image analysis is also performed on photomicrographs of thin sections to quantitively investigate the leaching of $\mathrm{Ca}(\mathrm{OH})_{2}$ due to deicer application.

\section{Materials and experimental methods Materials \\ Field mortars}

The studied field mortar samples were obtained from substrate slabs that were designed to support tactile warning tiles at a public transit facility in the Rocky Mountain Region of the US. The substrate slabs were placed in 2014 and samples were obtained in 2020 after the slabs had been in service for six winter seasons. Figure 1 shows the average annual snowfall accumulation in the contiguous US (US National Oceanic and Atmospheric Administration: https://www.noaa.gov). The average annual snowfall in the region where the samples are from is in the range of $122-182 \mathrm{~cm}$, and the exterior slabs were subject to frequent freeze-thaw cycles in winter. A deicer primarily consisting of $\mathrm{CaCl}_{2}$ was reportedly used in the first two winter seasons, while a deicer primarily consisting of $\mathrm{MgCl}_{2}$ was reportedly used in the following four winter seasons.

Two mortar samples designated as "undamaged field mortar" and "damaged field mortar" are shown in Fig. 2. The hard and compact undamaged field mortar was obtained from a relatively dry sheltered corner that did not see significant deicer application. The friable damaged field mortar was obtained from a wet unsheltered zone with significant deicer exposure. Both samples were fragmented during sampling. The damaged field mortar shows white secondary deposits on the fragment surface. Although the exact mixture design remains unknown, petrographic examinations indicate that the mortar samples are non-air-entrained and do not contain any supplementary cementitious materials (SCMs). The damaged field mortar has had long-term contact with 


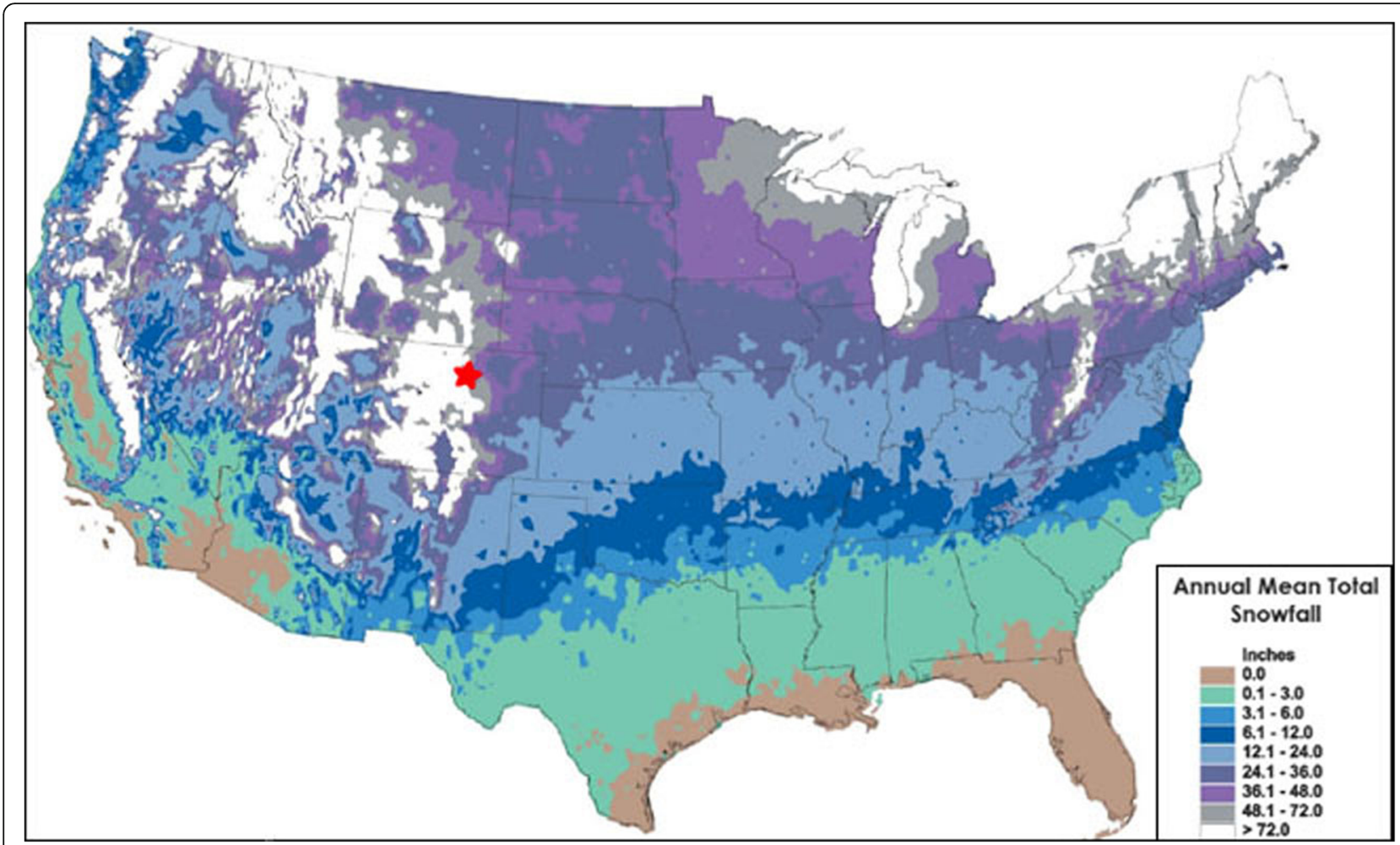

Fig. 1 Average annual snowfall map of the contiguous US from US National Oceanic and Atmospheric Administration (https://www.noaa.gov). The red star indicates the location of the field samples

deicer solutions through the edge of the tiles, as the top surface of the substrate slab is lower than the surrounding platform.

\section{Lab-cast cement paste and mortar}

Type I/II ordinary portland cement (OPC) was used to prepare an OPC paste and mortar in the lab for the comparative study with the field mortar. The fine aggregate was a siliceous sand with a nominal maximum size of $4.75 \mathrm{~mm}$ and an absorption of $2.84 \%$. Aggregates were corrected for water content before mixing. The OPC paste (P1) and mortar (M1) were mixed using a w/ $c$ of 0.40; the mortar had a sand-to-cement ratio of 2.0. The mixtures P1 and M1 were mixed using a benchtop mixer following ASTM C305, cast into 50-mm cubes and then cured in a moist room at $23^{\circ} \mathrm{C}$ for 28 days.
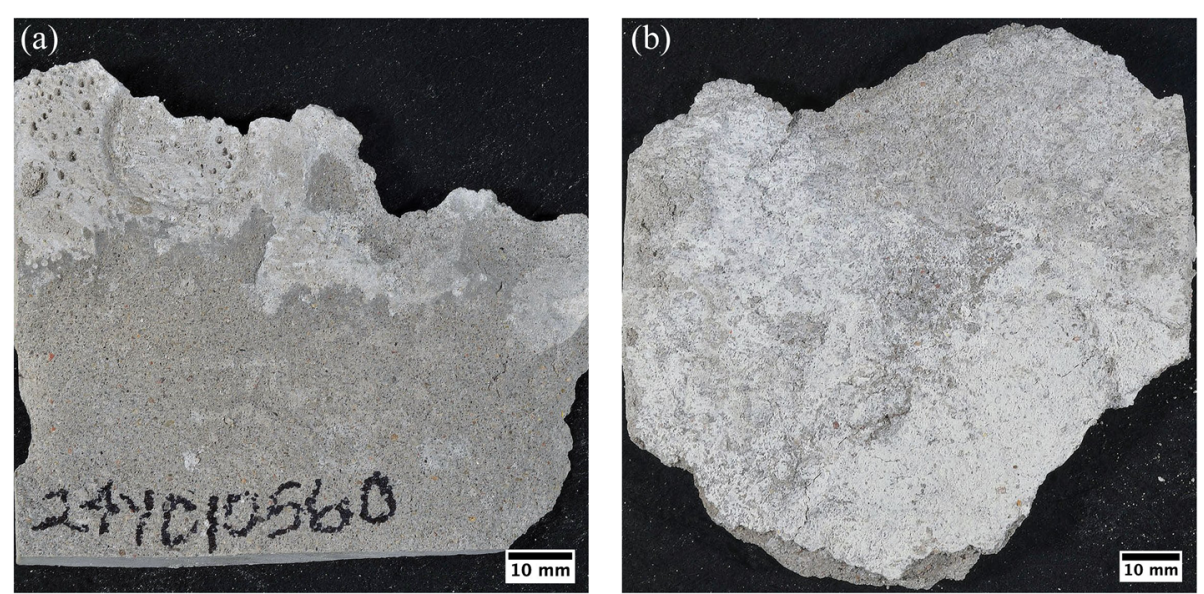

Fig. 2 The conditions of the as-received fragments of the undamaged field mortar (a) and the damaged field mortar (b), respectively 


\section{$\mathrm{CaCl}_{2}$ solution}

Since the damage induced by $\mathrm{MgCl}_{2}$ is limited to a shallow zone next to the exposure surface [7], the lab-cast $\mathrm{P} 1$ and $\mathrm{M} 1$ were only exposed to a $\mathrm{CaCl}_{2}$ solution during freeze-thaw cycles to mimic the damage by $\mathrm{CaCl}_{2}$ in the field. A commercial deicer $\mathrm{CaCl}_{2}$ with a purity $>95$ wt.\% was used to prepare solutions with a $\mathrm{CaCl}_{2}$ concentration of $25 \mathrm{wt} . \%$ by mixing the salt with tap water in the appropriate weight proportions.

\section{Experimental methods \\ Freeze-thaw cycles}

At the age of 28 days, P1 and M1 were completely submerged in $25 \mathrm{wt}$.\% $\mathrm{CaCl}_{2}$ solutions (liquid/solid ratio 0.7 by mass) in a sealed container and then moved into a freezer for $24 \mathrm{~h}$. Temperature was monitored in areas around the specimens during the $24-\mathrm{h}$ period; the recorded minimal temperature was $-8 \pm 1^{\circ} \mathrm{C}$, which is comparable to the average low temperature at the studied field location during the winter. After $24 \mathrm{~h}$ in the freezer, the container was removed from the freezer and kept under ambient conditions $\left(25 \pm 1^{\circ} \mathrm{C}\right)$ for $24 \mathrm{~h}$, after which the procedure was repeated. Thus, each freezethaw cycle lasted $48 \mathrm{~h}$. Although the ambient temperature was below $0{ }^{\circ} \mathrm{C}$ for $24 \mathrm{~h}$ during each freezing stage, the thermocouples inserted into specimens indicated that the specimen temperature remained below $0{ }^{\circ} \mathrm{C}$ for only about $7 \mathrm{~h}$. Considering the high $\mathrm{CaCl}_{2}$ concentration of the submersion solution, it is unlikely that actual freezing occurred.

Fine cracks (minor damage) were initially detected on the edges of P1 cubes after eight freeze-thaw cycles and the specimen disintegrated after 51 cycles (failure). Fine cracks were observed in M1 after seven cycles; M1 became friable and exhibited signs of severe damage (significant spalling and swelling) after 53 cycles and disintegrated after 142 cycles (failure). Figure 3 shows the collected specimens for petrographic examinations
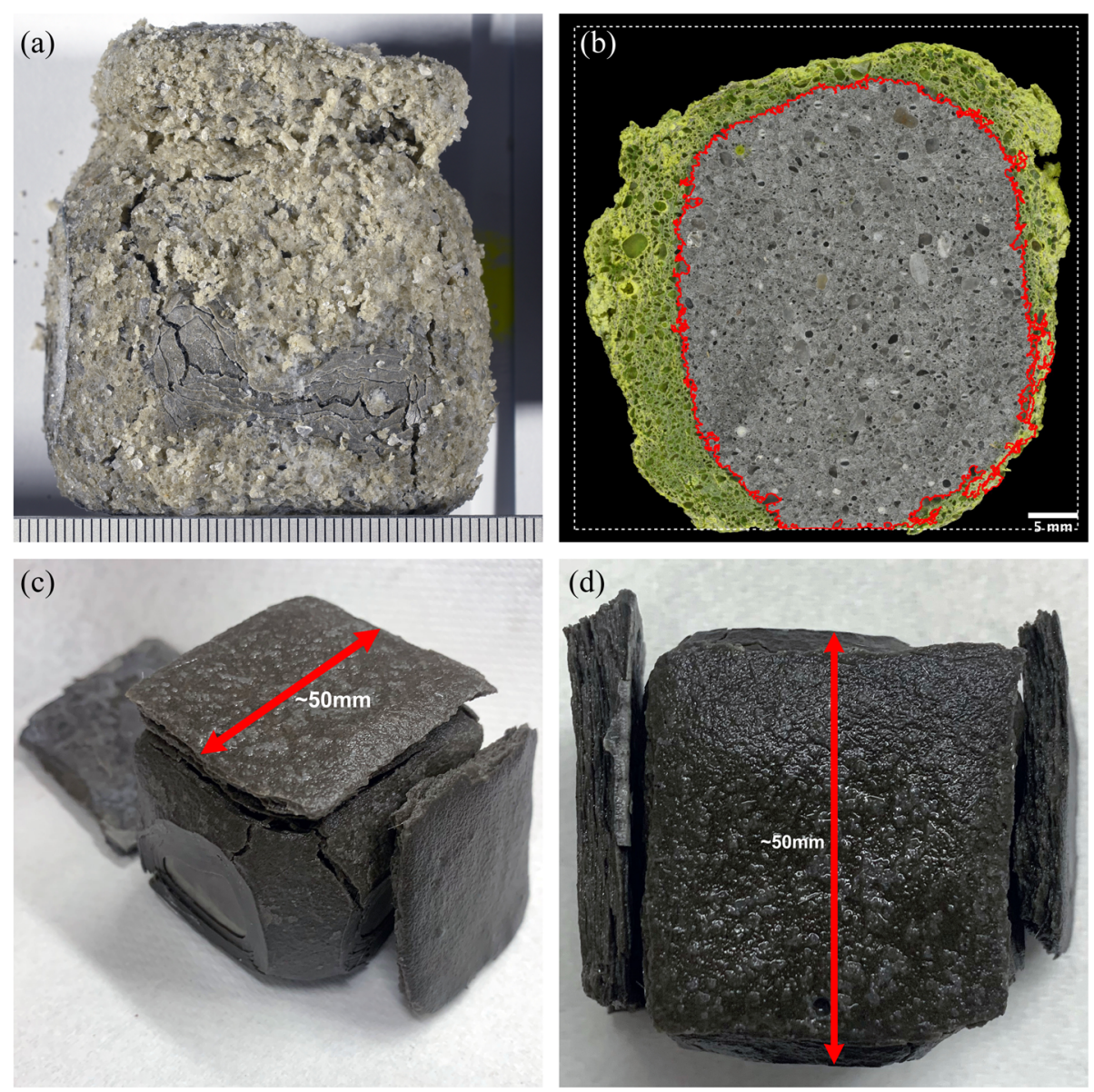

Fig. 3 a Photograph showing the condition of the lab-cast mortar after 142 freeze-thaw cycles under the submersion of a 25 wt.\% CaCl 2 solution. Scale in millimeters. $\mathbf{b}$ Reflected light photomicrograph (RLP) of the polished surface of the lab-cast mortar. White square and red curve indicate the original size and the remaining intact zone of the sample, respectively. The yellow green color in (b) indicates the epoxied damage zone. $\mathbf{c}$ and $\mathbf{d}$ Photographs showing the condition of the lab-cast paste after 51 freeze-thaw cycles under the submersion of a 25 wt.\% $\mathrm{CaCl}_{2}$ solution. Note the delamination near the exposure surfaces 
after disintegration (51 cycles for P1 and 142 cycles for M1).

\section{Optical microscopy (OM)}

Optical microscopy was conducted on a polished slab and a thin section that represents a longitudinal cross section of each mortar sample (two field mortars and one lab-cast mortar) according to ASTM C856-20 [28]. Epoxy that contains fluorescent dye was used to stabilize the damaged field and lab-cast mortars prior to the polished slab preparation. Thin sections $(46 \mathrm{~mm}$ by 26 $\mathrm{mm}$ ) of all samples were impregnated with an epoxy containing fluorescent dye and ground and polished to a thickness of $20-25 \mu \mathrm{m}$ by an automatic thin section machine (PELCON). A stereomicroscope (Nikon ${ }^{\text {Tw }}$ SMZ-25) and a petrographic microscope $\left(\mathrm{Nikon}^{\text {Th }}\right.$ E-Pol 600) were used for reflected light microscopy on the polished slabs and transmitted light microscopy on thin sections, respectively.

\section{Scanning electron microscopy coupled with energy dispersive X-ray spectrometry (SEM-EDX)}

A scanning electron microscope (FEI ${ }^{\mathrm{m}}$ Quanta 250) coupled with an energy dispersive X-ray (EDX, Thermo Scientific $^{\text {Tx }}$ UltraDry EDS) was used to examine the morphology and elemental compositions of secondary deposits that line cracks, microcracks and voids in the samples. Uncoated fracture surfaces of each sample were examined in the low vacuum $(\sim 70 \mathrm{~Pa})$ mode using an accelerating voltage of $15 \mathrm{kV}$ at a working distance of 10 $\mathrm{mm}$.

\section{Damage quantification}

Figure 4 shows the cracking patterns in the damaged field mortar, lab-cast mortar and paste after exposure to freeze-thaw cycles and deicers. Each sample exhibits a network of interconnected cracks $(0.1-1 \mathrm{~mm}$ in width) and microcracks $(<0.1 \mathrm{~mm}$ in width). The crack and microcrack planes are subparallel to the exposure
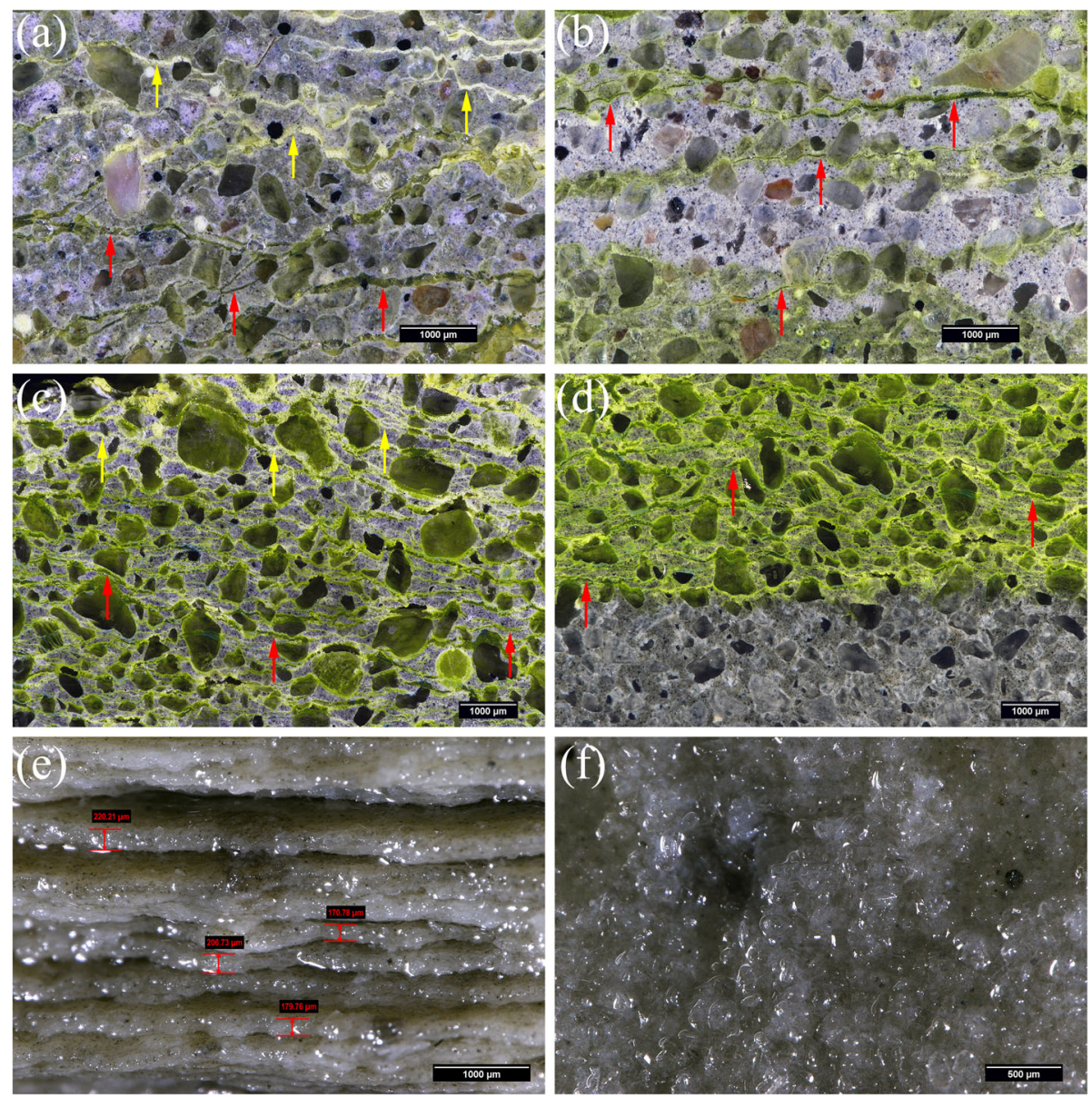

Fig. 4 a-d Reflected light photomicrographs of the polished surface of the damaged field mortar (a and $\mathbf{b}$ ) and lab-cast mortar (c and $\mathbf{d}$ ), respectively, showing horizontal cracks/microcracks at two different depths from the exposure surface. Zones in (a) and (c) are closer to the exposure surface. Yellow and red arrows indicate cracks/microcracks with and without secondary deposits, respectively. e Fresh delamination sheets in the damaged lab-cast paste. $\mathbf{f}$ Transparent secondary deposits on the surface of the delamination sheet in (e) 
surface and cut around aggregate particles, which consist mostly of quartz grains. Without the restraint imposed by fine aggregate particles, the crack planes in the labcast paste P1 are parallel to each other in the delamination zone (Fig. 3c-d), and each delamination sheet in P1 has approximately the same thickness of $200 \pm 25 \mu \mathrm{m}$. These characteristics are typical of damaged observed from freeze-thaw cycles [23].

Secondary deposits were observed to fill cracks and microcracks near the exposed surface in each sample, as shown in Fig. 4a, c and f. This is consistent with the formation of $\mathrm{Ca}-\mathrm{Oxy}$ due to the application of $\mathrm{CaCl}_{2}$ [16]. The secondary deposits are white and translucent on the polished surface of the two mortars (in Fig. 4a and c), while they are transparent on the fresh surface of the delamination sheet in the paste (in Fig. 4f). The difference in appearance is likely related to drying effects during the preparation of the polished surface [16].

Figure 5a-d show bright green cracks/microcracks that are filled with epoxy containing fluorescent dye under the ultraviolent light. Since very little epoxy is able to penetrate the paste from the cracks/microcracks, the paste matrix and aggregate are dark green to black as background. This enhanced contrast between the cracks/microcracks and matrix affords an opportunity to quantify cracking through image analysis. Cracks and microcracks can be automatically recognized and extracted on the polished surfaces using a plugin "Ridge Detection" in ImageJ [29], as illustrated in Fig. 5e-h. The "Ridge Detection" plugin requires three parameters: (a) line width; (b) highest grayscale value of the line; and (c) lowest grayscale value of the line. After several trials, the values of the three parameters were determined as 15 pixels, 255 and 80 , respectively, for the best detection. The above process outputs three important parameters regarding the cracking characteristics, i.e., the length, mean width and orientation of each crack/microcrack.

As geometric features of a partially connected crack network, the orientations of cracks/microcracks are closely related to the fracture process and progress in solids [21]. Figure 5i-l show rose diagrams of crack/ microcrack orientations at different depths in the damaged field and lab-cast mortars. The statistical data of cracking orientations further confirms the preferred cracking direction that tends to be parallel to the exposure surface of both field and lab-cast mortars. There is a variation of $30-45^{\circ}$ in the preferred orientation due to the constraints of sand particles in the mortar.

Cracking length and mean width are direct measures of the extent of material damage. They are used to calculate crack density $\left(l, \mathrm{~mm} / \mathrm{mm}^{2}\right)$ and crack area fraction (s, unitless) as follows:

$$
\begin{aligned}
& l=\frac{\sum L_{\text {crack }}}{S S} \\
& s=\frac{\sum L_{\text {crack }} \cdot W_{\text {crack }}}{S S}
\end{aligned}
$$

where, $L_{\text {crack }}(\mathrm{mm})$ and $W_{\text {crack }}\left(\mathrm{mm}^{2}\right)$ are the length and mean width of a crack/microcrack in the selected zone with an area of $S S\left(\mathrm{~mm}^{2}\right)$. Although somewhat differing definitions of crack density have been adopted in previous studies $[19,21]$, this paper uses Eq. 4 to define the crack density for the following discussion.

Figure 6 summarizes the measured results in randomly selected zones (Fig. 5) at two different depths of each damaged mortar. In both damaged mortars, the area further from the exposure surface shows a lower crack density and area fraction, which indicates the progression of damage with depth. It is impossible to obtain the absolute depth of the selected zones since the original exposure surface is missing due to the severe damage. Compared to the damaged field mortar, the lab-cast mortar shows approximately 3-4 times higher crack density and 1-3 times higher crack area, indicating more damage occurred under the accelerated exposure conditions realized in the laboratory. The phase diagram for the $\mathrm{Ca}(\mathrm{OH})_{2}-\mathrm{CaCl}_{2}-\mathrm{H}_{2} \mathrm{O}$ system demonstrates that $\mathrm{Ca}$ Oxy is a stable phase in a $25 \mathrm{wt} . \% \mathrm{CaCl}_{2}$ solution at a temperature lower than $40^{\circ} \mathrm{C}$ [30]. This implies that the formed $\mathrm{Ca}-\mathrm{Oxy}$ was able to constantly damage the labcast mortar throughout each freeze-thaw cycle $\left(-8{ }^{\circ} \mathrm{C}\right.$ to $25^{\circ} \mathrm{C}$ ). In the field, external factors, such as loss of the deicer solutions from drainage and dilution of these solutions from rainfall, reduce the potential for $\mathrm{Ca}-\mathrm{Oxy}$ to be a stable phase. Additional Ca-Oxy destabilization also occurs from carbonation, which is minimized in the lab due to constant submersion in the deicer solution [16].

\section{Mineralogical alteration quantification Secondary deposits}

SEM-EDX was used to examine the secondary deposits observed in the damaged field mortar and lab-cast paste after exposure to $\mathrm{CaCl}_{2}$ deicer solutions. To avoid the chemical and physical alteration of secondary deposits during sample preparation, only fresh fracture surfaces of each sample were examined. Figure 7 shows the morphology of secondary deposits in different locations of the damaged field mortar. Although a well-polished surface renders EDX semi-quantitative analyses at best, one can still recognize the elemental composition of phases of interest on fracture surfaces. Multiple secondary deposits were observed in the damaged field mortar as follows: 

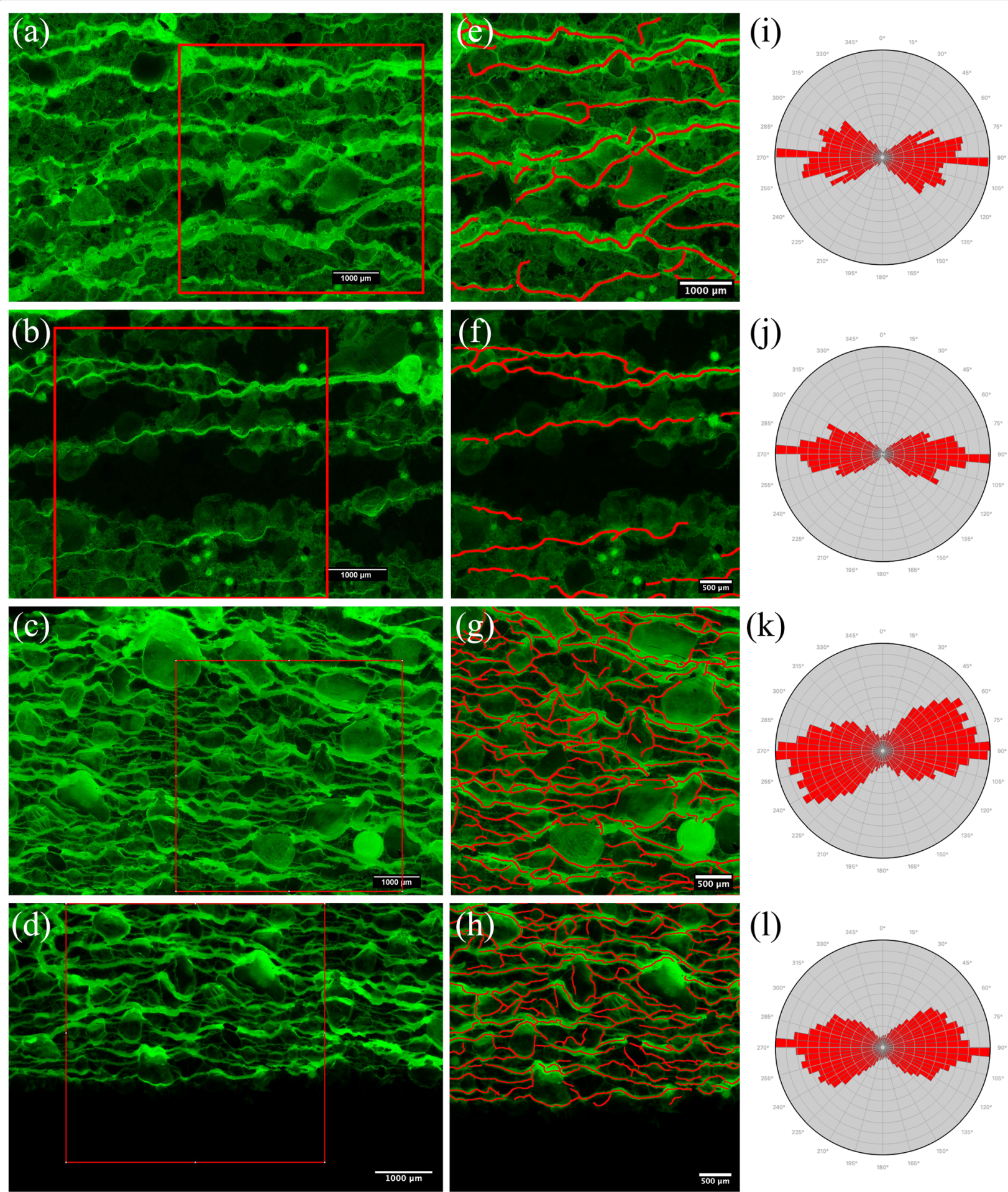

(1)

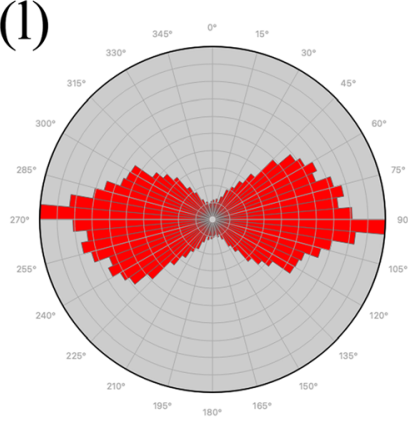

Fig. 5 a and $\mathbf{b}$ Fluorescent reflected light photomicrographs (FRLP) of the polished surface of the damaged field mortar showing cracks/ microcracks in the upper and lower zones from the top surface, respectively. $\mathbf{c}$ and $\mathbf{d}$ FRLP of the polished surface of the lab-cast mortar showing cracks/microcracks in the closer (outward) and further (inward) zones from the outer surface, respectively. e-h ldentified crack network in the red zone in (a-d). i-l Rose diagrams showing the cracking orientation in (e-h) 


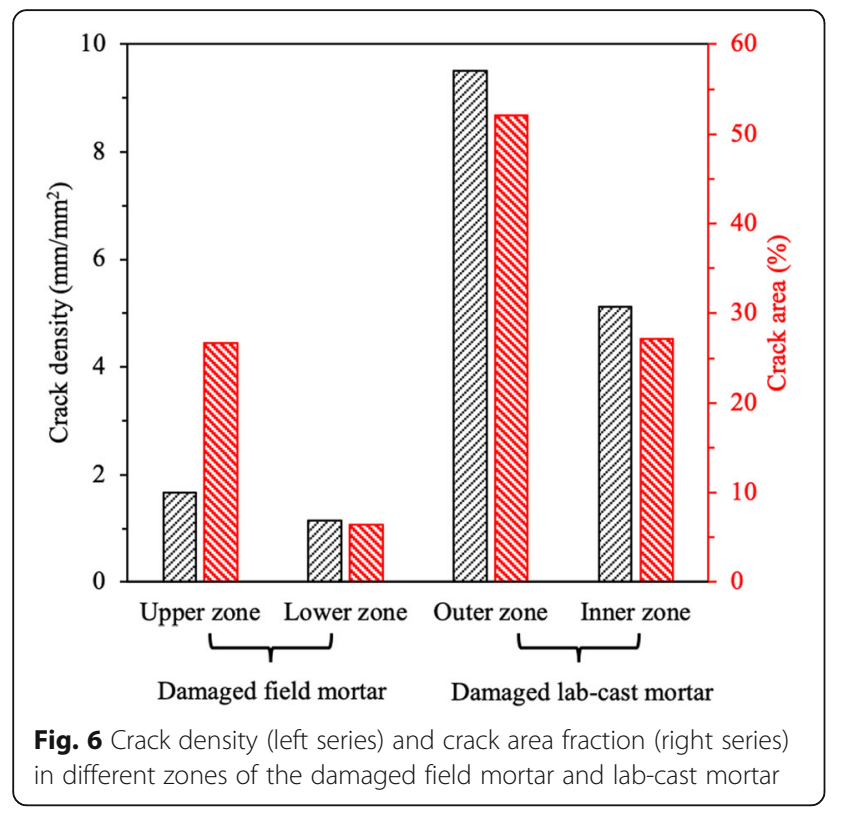

(a) Friedel's salt. As the external chloride ions penetrate the cement-based mortar, they react with calcium monosulfoalunimate (AFm) and its iron analog to form Friedel's salt [31], which is distributed in the paste matrix in Fig. 7a.

(b) Ettringite. Clusters of fibrous secondary ettringite were observed filling air voids, as shown in Fig. 7b. The conversion of AFm to Friedel's salt by ionic exchange releases sulfate ions, which can further react with the remaining AFm to form secondary ettringite [32, 33]. The presence of external deicers in the pore solution leads to a relatively high internal humidity in the mortar, and this helps stabilize ettringite that has a high water content (32 $\mathrm{H}_{2} \mathrm{O}$ molecules) [34].

(c) $\mathrm{Ca}-\mathrm{O} x y$. Ca-Oxy forms when $\mathrm{CaCl}_{2}$ deicer reacts with $\mathrm{Ca}(\mathrm{OH})_{2}$ in the cement paste (Eq. 3). Ca-Oxy manifests as prismatic crystals that were observed filling air voids and lining cracks/microcracks in Fig. 7b-c. This is consistent with previous observations by Galan et al. [35]. The Ca-Oxy crystals exhibit a series of developed microcracks parallel to
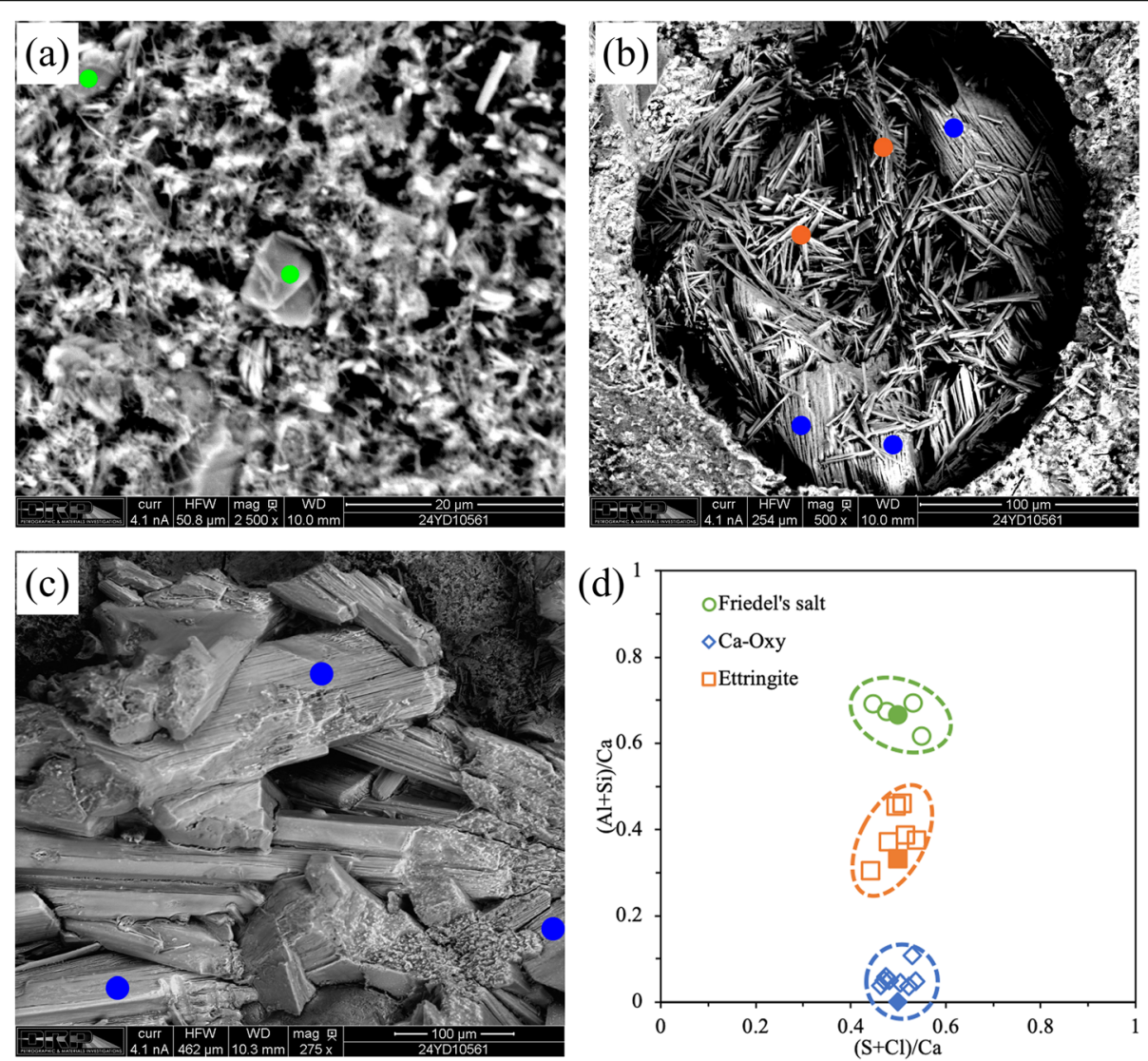

Fig. 7 a-c Backscattered electron (BSE) images of secondary deposits in a the paste matrix, $\mathbf{b}$ an air void and $\mathbf{c}$ a fresh fracture surface, respectively. Green circles: Friedel's salt; blue diamonds: Ca-Oxy; orange squares: ettringite. d Atomic ratios obtained from EDX spectra in zones in (a-c). The solid shapes indicate the theoretical composition of the corresponding minerals 
the prism axis, which may be related to partial dehydration of the crystals in the SEM vacuum chamber [35].

The observed secondary deposits were chemically analyzed and verified using EDX in Fig. 7d, which shows that they have comparable elemental ratios to the corresponding theoretical formulas. No evidence of significant deposits of brucite or M-S-H was observed within in the damaged field mortar. This is consistent with brucite blocking pores at the exposure surface [7, 12].

The sensitivity of Ca-Oxy morphology to drying is further investigated in the lab-cast paste P1. Figure 8 shows the different $\mathrm{Ca}-\mathrm{Oxy}$ crystals that are freshly obtained from P1 and vacuum dried in the SEM chamber at a vacuum level of $\sim 70 \mathrm{~Pa}$ for $12 \mathrm{~h}$. Compared to the fresh $\mathrm{Ca}-\mathrm{Oxy}$ crystals, the dried $\mathrm{Ca}-\mathrm{Oxy}$ crystals become white and translucent to opaque (Fig. 8a-b), which is related to the white secondary deposits filling cracks/microcracks on the polished surfaces of mortars in Fig. 4a and c. Moreover, the dried Ca-Oxy prisms shrank and further cracked due to the loss of water, as shown in Fig. 8c-d. These findings are consistent with previously reported observations [35]. EDX analysis in Fig. 8e-f shows that the majority of dried Ca-Oxy crystals maintain the same elemental composition as the fresh Ca-Oxy crystals.
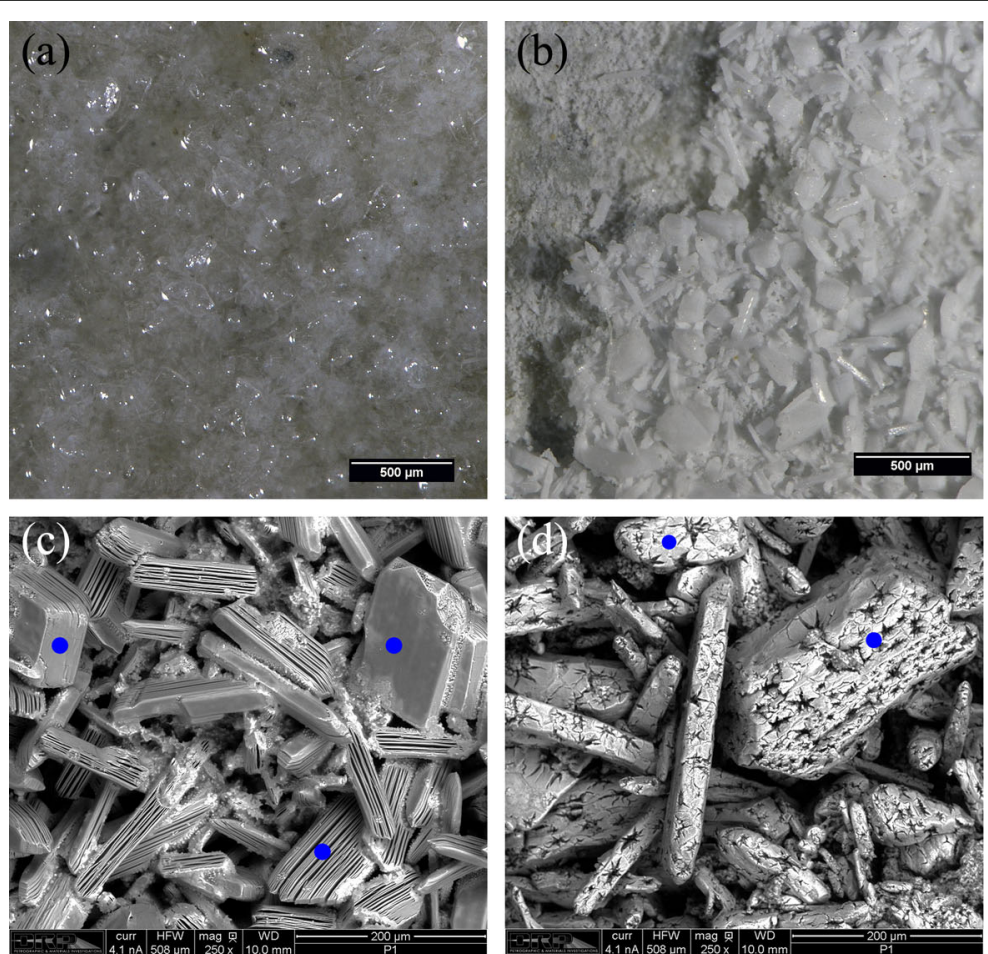

(e)

(f)
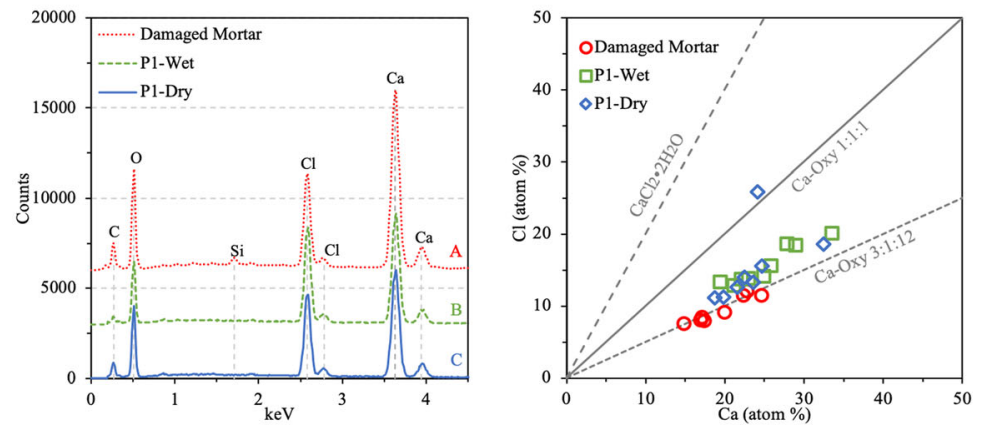

Fig. 8 a-b RLP and $\mathbf{c}$-d BSE images of Ca-Oxy (blue solid dots) on a fracture surface of the damaged lab-cast paste in (a/c) an originally wet condition and (b/d) a dried condition, respectively. e EDX spectra obtained from zones in Figs. 7c and 8c-d. $\mathbf{f}$ Relationship between Ca and Cl contents of Ca-Oxy observed from EDX overlaid with theoretical Ca-Oxy formulae 
However, a portion of dried Ca-Oxy crystals may have been converted to a type of calcium oxychloride without water, e.g. $\mathrm{Ca}(\mathrm{OH})_{2} \cdot \mathrm{CaCl}_{2}$, as shown in Fig. $8 \mathrm{f}$.

\section{$\mathrm{Ca}(\mathrm{OH})_{2}$ leaching}

Figure 9 highlights $\mathrm{Ca}(\mathrm{OH})_{2}$ present in the undamaged and damaged field mortars via transmitted crosspolarized light microscopy with the first order retardation plate. The $\mathrm{Ca}(\mathrm{OH})_{2}$ crystals are in first order yellow and second order blue interference colors. The undamaged field mortar shows $\mathrm{Ca}(\mathrm{OH})_{2}$ crystals evenly distributed in the paste matrix, while $\mathrm{Ca}(\mathrm{OH})_{2}$ crystals are scarce in the damaged field mortar paste. This finding directly confirms that the deicer application, especially $\mathrm{CaCl}_{2}$, can lead to the leaching of $\mathrm{Ca}(\mathrm{OH})_{2}$ in the field due to the reduction in $\mathrm{pH}$ and the formation of Ca-Oxy [7, 33]. $\mathrm{MgCl}_{2}$ deicer can also consume $\mathrm{Ca}(\mathrm{OH})_{2}$ due to the formation of brucite, but its influence is limited in areas adjacent to the exposure surface considering the absence of brucite in the bulk of the examined samples.

Since $\mathrm{Ca}(\mathrm{OH})_{2}$ crystals show distinct colors from the other hydrates in the paste matrix in Fig. 9a and c, image segmentation can be performed to quantify the volume (area) fraction of $\mathrm{Ca}(\mathrm{OH})_{2}$ crystals in the paste matrix. First, the aggregate particles were selected and excluded (green areas in Fig. 9b and d) manually in ImageJ before the segmentation. The remaining section in each image truly represents the paste matrix. Three classes of components are categorized as follows: (a) $\mathrm{Ca}(\mathrm{OH})_{2}$ crystals that are in in first order yellow and second order blue interference color; (b) the other hydrates that are in purple as background; and (c) the unhydrated cement particles that are opaque in dark brown to black. The image segmentation were performed using the plugin "Trainable Weka Segmentation" in ImageJ [36]. This plugin provides pixel-based segmentation using multiple machine learning algorithms together with a set of selected image features. Three classes of pixels were defined based on the above three components in the paste. After different areas were selected and assigned to each class as inputs, the plugin automatically produces satisfactory segmentation after a few training instances, as shown in Fig. $9 \mathrm{~b}$ and d. The zoomed in areas in Fig. 9e-h indicate that the machine learning based segmented areas agree well with the actual corresponding components.

Figure 10 plots the volumetric (area) fraction of $\mathrm{Ca}(\mathrm{OH})_{2}$ normalized to the total hydrates in the paste. Compared to the undamaged field mortar, the damaged field mortar shows a significant reduction of $86.4 \%$ in $\mathrm{Ca}(\mathrm{OH})_{2}$ based on the above image analysis. The analyzed $\mathrm{Ca}(\mathrm{OH})_{2}$ volumetric faction $(26.7 \%)$ in the hydrates of the undamaged field mortar is similar to that of $27.2 \%$ reported by Liao et al. [37]. This shows the reliability and feasibility of applying optical microscopy coupled with image analysis to quantitively investigate the chemical alteration caused by deicers. This methodology can be further extended to analyze other durability-related microstructural alteration if a distinct feature can be defined under microscopes.
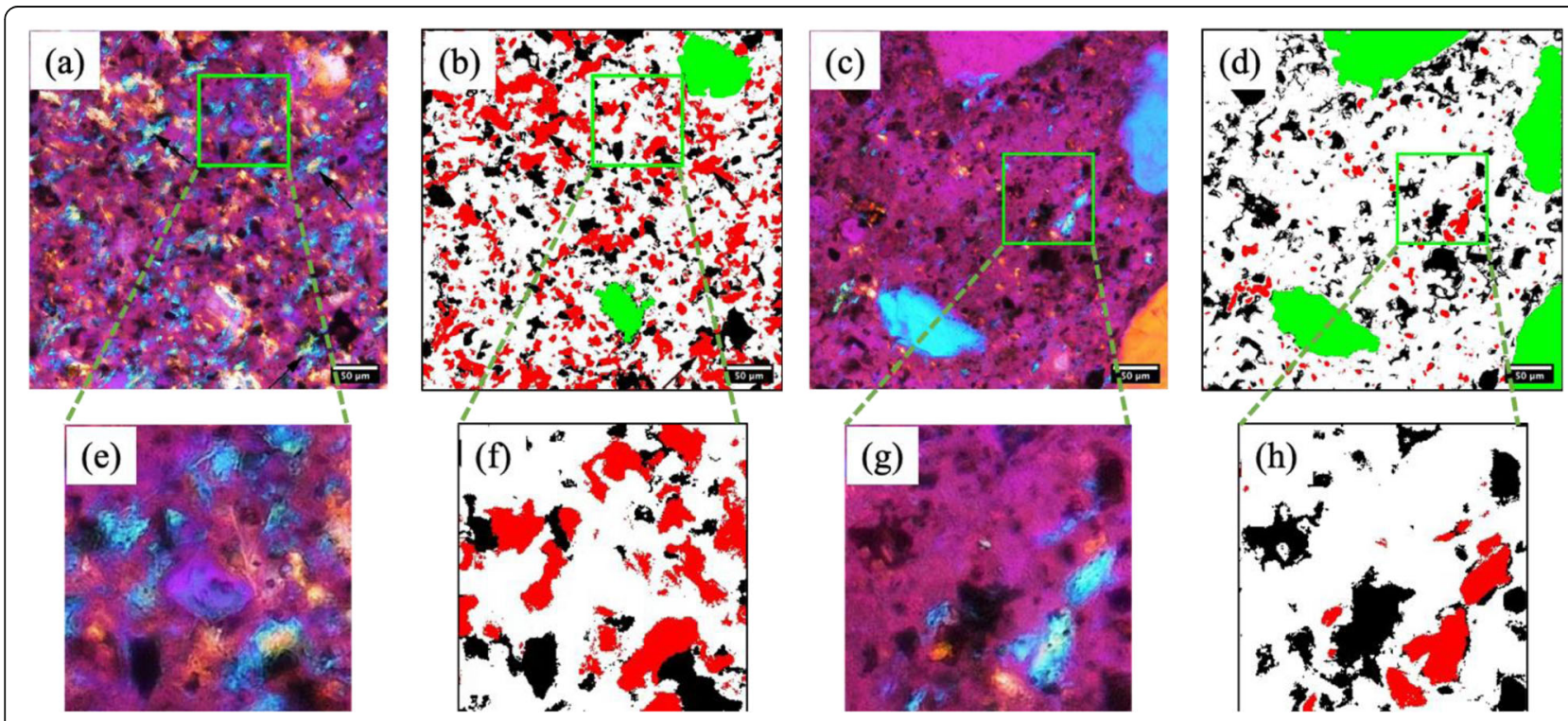

Fig. 9 a\&c Transmitted light photomicrographs showing paste in the middle of $\mathbf{a}$ undamaged field mortar and $\mathbf{c}$ damaged field mortar, respectively, in cross-polarized light with the gypsum first order retardation plate inserted. b\&d Segmentation images of the photomicrographs in (a and c) using 2D Trainable Weka Segmentation in ImageJ [36]. e-h Zoomed-in images of the corresponding zones in (a-d). The size of the zone in (e-h) is $100 \mu \mathrm{m}$ by $100 \mu \mathrm{m}$ 


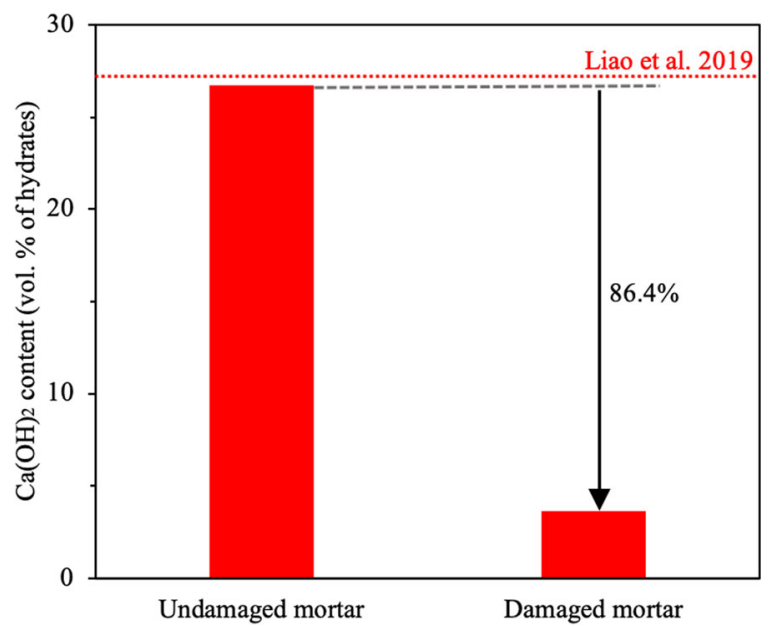

Fig. 10 Quantification of $\mathrm{Ca}(\mathrm{OH})_{2}$ contents in the mortars using image analysis. The red dotted line indicates the value from Ref. [37]

\section{Conclusions}

This paper demonstrates the utility of combining petrographic methods with image analysis to quantify damage of cementitious materials exposed to freeze-thaw cycles and chloride-based deicers. The damaged field and labcast mortars show similar cracking patterns including: (a) a network of interconnected cracks/microcracks that are parallel to the exposure surface; and (b) lowered crack density over the depth. Both damaged field and lab-cast mortars show a variation of $30-45^{\circ}$ in the preferred orientation due to the constraints of sand particles. Compared to the damaged field mortar, the lab-cast mortar shows 3-4 times higher crack density and 1-3 times higher crack area fraction because the accelerated lab exposure conditions are far more severe than the field exposure conditions.

SEM-EDX analysis confirms the elemental compositions of three distinct secondary deposits: Friedel's salt, ettringite and $\mathrm{Ca}-\mathrm{Oxy}$. The altered appearance of $\mathrm{Ca}-$ Oxy after drying demonstrates the influence of sample preparation on the formed Ca-Oxy.

Transmitted cross-polarized light microscopy with the first order retardation plate can be used to perform image segmentation and quantify the volume fraction of $\mathrm{Ca}(\mathrm{OH})_{2}$ in the cement-based materials. Compared to the undamaged field mortar, the damaged field mortar shows a reduction of $86.4 \%$ in $\mathrm{Ca}(\mathrm{OH})_{2}$ content, suggesting the significant leaching of $\mathrm{Ca}(\mathrm{OH})_{2}$ due to the formation of Ca-Oxy.

\section{Abbreviations}

Ca-Oxy: Calcium oxychloride; M-S-H: Magnesium silicate hydrate; FM: Fluorescence microscopy; OM: Optical microscopy; SEM: Scanning electron microscopy; EDX: Energy dispersive X-ray spectrometry; ASR: Alkalisilica reaction; SCM: Supplementary cementitious material; OPC: Ordinary portland cement; FRLP: Fluorescent reflected light photomicrograph

\section{Acknowledgements}

The authors gratefully thank the assistance of Mr. Gaines Green and Ms. Grace Guryan for sample preparation at DRP, A Twining Company.

\section{Authors' contributions \\ Chunyu Qiao: Conceptualization, Methodology, Investigation, Formal analysis, Resources, Writing Original Draft, Supervision, Project administration. Nima Hosseinzadeh: Investigation, Resources, Review \& Editing. Prannoy Suraneni: Investigation, Resources, Review \& Editing, Funding acquisition. Sihang Wei: Investigation, Review \& Editing. David Rothstein: Investigation, Project administration, Review \& Editing. The author(s) read and approved the final manuscript.}

\section{Funding}

Funding assistance from Ready Mixed Concrete Research and Education Foundation for the project "The role of air content and supplementary cementitious materials replacement in deicing salt joint damage in concrete" is acknowledged.

\section{Availability of data and materials}

Some or all data generated or used during the study are available from the corresponding author by request.

\section{Declarations}

\section{Competing interests}

The authors declare that they have no competing interests.

\section{Author details}

${ }^{1}$ DRP, A Twining Company, Boulder, CO 80301, USA. ²Department of Civil, Architectural and Environmental Engineering, University of Miami, Coral Gables, FL 33146, USA. Bintong Engineering, Shenzhen 518052, Guangdong, China.

Received: 23 February 2021 Accepted: 19 March 2021

Published online: 14 April 2021

\section{References}

1. Yehia S, Tuan CY (1998) Bridge deck deicing. In: Transportation conference proceedings. lowa State University, Ames, pp 51-57

2. Fischel M (2001) Evaluation of selected deicers based on a review of the literature CDOT-DTD-R-2001-15. Colorado Department of Transportation, Denver

3. Mussato BT, Gepraegs OK, Farnden G (2004) Relative effects of sodium chloride and magnesium chloride on reinforced concrete: state of the art. Transp Res Rec 1866(1):59-66. https://doi.org/10.3141/1866-08

4. Ramakrishna DM, Viraraghavan T (2005) Environmental impact of chemical deicers - a review. Water Air Soil Pollut 166(1):49-63. https://doi.org/10.1 007/s11270-005-8265-9

5. Ababneh A, Benboudjema F, Xi YP (2003) Chloride penetration in nonsaturated concrete. J Mater Civ Eng 15(2):183-191. https://doi.org/10.1 061/(Asce)0899-1561(2003)15:2(183)

6. Bastidas-Arteaga E, Chateauneuf A, Sánchez-Silva M, Bressolette P, Schoefs F (2011) A comprehensive probabilistic model of chloride ingress in unsaturated concrete. Eng Struct 33(3):720-730. https://doi.org/10.1016/j. engstruct.2010.11.008

7. Qiao C, Suraneni P, Tsui Chang M, Weiss J (2018) Damage in cement pastes exposed to $\mathrm{MgCl}_{2}$ solutions. Mater Struct 51(3):74. https://doi.org/10.1617/ s11527-018-1191-2

8. Qiao C, Suraneni P, Weiss J (2018) Flexural strength reduction of cement pastes exposed to $\mathrm{CaCl}_{2}$ solutions. Cem Concr Compos 86:297-305. https:// doi.org/10.1016/j.cemconcomp.2017.11.021

9. Shi X, Fay L, Peterson MM, Yang Z (2010) Freeze-thaw damage and chemical change of a portland cement concrete in the presence of diluted deicers. Mater Struct. 43(7):933-46. https://doi.org/10.1617/s1152 7-009-9557-0

10. Sutter L, Peterson K, Touton S, Van Dam T, Johnston D (2006) Petrographic evidence of calcium oxychloride formation in mortars exposed to magnesium chloride solution. Cem Concr Res 36(8):1533-1541. https://doi. org/10.1016/j.cemconres.2006.05.022 
11. Farnam Y, Wiese A, Bentz D, Davis J, Weiss J (2015) Damage development in cementitious materials exposed to magnesium chloride deicing salt. Constr Build Mater 93:384-392. https://doi.org/10.1016/j.conbuildmat.2015. 06.004

12. Qiao C, Ni W, Wang Q, Weiss J (2018) Chloride diffusion and wicking in concrete exposed to $\mathrm{NaCl}$ and $\mathrm{MgCl}_{2}$ solutions. J Mater Civ Eng 30(3): 04018015. https://doi.org/10.1061/(ASCE)MT.1943-5533.0002192

13. Chatterji S (1978) Mechanism of the $\mathrm{CaCl}_{2}$ attack on portland cement concrete. Cem Concr Res 8(4):461-467. https://doi.org/10.1016/0008-884 6(78)90026-1

14. Smith SH, Qiao C, Suraneni P, Kurtis KE, Weiss WJ (2019) Service-life of concrete in freeze-thaw environments: critical degree of saturation and calcium oxychloride formation. Cem Concr Res 122:93-106. https://doi.org/1 0.1016/j.cemconres.2019.04.014

15. Jones C, Ramanathan S, Suraneni P, Hale WM (2020) Calcium oxychloride: a critical review of the literature surrounding the formation, deterioration, testing procedures, and recommended mitigation techniques. Cem Concr Compos 113:103663. https://doi.org/10.1016/j.cemconcomp.2020.103663

16. Peterson K, Julio-Betancourt G, Sutter L, Hooton RD, Johnston D (2013) Observations of chloride ingress and calcium oxychloride formation in laboratory concrete and mortar at $5^{\circ} \mathrm{C}$. Cem Concr Res 45:79-90. https:// doi.org/10.1016/j.cemconres.2013.01.001

17. Collepardi M, Coppola L, Pistolesi C (1994) Durability of concrete structures exposed to $\mathrm{CaCl}_{2}$ based deicing salts. In: Proceedings of the 3rd CANMENT/ $\mathrm{ACl}$ international conference, France. American Concrete Institute, Farmington Hills, pp 107-120

18. Hornain H, Marchand J, Ammouche A, Commène JP, Moranville M (1996) Microscopic observation of cracks in concrete - a new sample preparation technique using dye impregnation. Cem Concr Res 26(4):573-583. https:// doi.org/10.1016/0008-8846(96)00032-4

19. Ammouche A, Breysse D, Hornain H, Didry O, Marchand J (2000) A new image analysis technique for the quantitative assessment of microcracks in cement-based materials. Cem Concr Res 30(1):25-35. https://doi.org/10.101 6/S0008-8846(99)00212-4

20. Litorowicz A (2006) Identification and quantification of cracks in concrete by optical fluorescent microscopy. Cem Concr Res 36(8):1508-1515. https://doi. org/10.1016/j.cemconres.2006.05.011

21. Zhou C, Li K, Pang X (2012) Geometry of crack network and its impact on transport properties of concrete. Cem Concr Res 42(9):1261-1272. https:// doi.org/10.1016/j.cemconres.2012.05.017

22. Schindelin J, Arganda-Carreras I, Frise E, Kaynig V, Longair M, Pietzsch T, Preibisch S, Rueden C, Saalfeld S, Schmid B, Tinevez J-Y, White DJ, Hartenstein V, Eliceiri K, Tomancak P, Cardona A (2012) Fiji: an open-source platform for biological-image analysis. Nat Methods 9(7):676-682. https:// doi.org/10.1038/nmeth.2019

23. Walker HN, Lane DS, Stutzman PE (2006) Petrographic methods of examining hardened concrete: a petrographic manual. Federal Highway Administration, McLean

24. Wong HS, Poole AB, Wells B, Eden M, Barnes R, Ferrari J, Fox R, Yio MHN, Copuroglu O, Guðmundsson G, Hardie R, Jakobsen UH, Makoubi K, Mitchinson A, Raybould P, Strongman J, Buenfeld NR (2020) Microscopy techniques for determining water-cement (w/C) ratio in hardened concrete: a round-robin assessment. Mater Struct 53(2):25. https://doi.org/10.1617/s11 527-020-1458-2

25. Qiao C, Rothstein D (2020) Microstructural evaluation of durability of different cementitious mixtures in microbial induced corrosion environments. In: Paper presented at the XV international conference on durability of building materials and components, Barcelona, Spain, October, 20-23, 2020

26. Katayama T, Tagami M, Sarai Y, Izumi S, Hira T (2004) Alkali-aggregate reaction under the influence of deicing salts in the Hokuriku district, Japan. Mater Charact 53(2):105-122. https://doi.org/10.1016/j.matchar.2004.07.003

27. Rothstein D, Qiao C (2020) Accelerated expansion test sample report: DRP. In: Saouma VE (ed) Diagnosis \& prognosis of AAR affected structures: stateof-the-art report of the RILEM technical committee 259-ISR, RILEM state-ofthe-art reports, vol 31, 1st edn. RILEM, p 594. https://doi.org/10.1007/978-3030-44014-5_16

28. ASTM C856 / C856M-20 (2020) Standard practice for petrographic examination of hardened concrete. ASTM International, West Conshohocken. https://doi.org/10.1520/C0856_C0856M-20
29. Steger C (1998) An unbiased detector of curvilinear structures. IEEE Trans Pattern Anal Mach Intell 20(2):113-125. https://doi.org/10.1109/34.659930

30. Qiao C, Suraneni $P$, Weiss J (2018) Phase diagram and volume change of the $\mathrm{Ca}(\mathrm{OH})_{2}-\mathrm{CaCl}_{2}-\mathrm{H}_{2} \mathrm{O}$ system for varying $\mathrm{Ca}(\mathrm{OH})_{2} / \mathrm{CaCl}_{2}$ molar ratios. J Mater Civ Eng 30(2):04017281. https://doi.org/10.1061/(ASCE)MT.1943-5533. 0002145

31. Suryavanshi AK, Scantlebury JD, Lyon SB (1996) Mechanism of Friedel's salt formation in cements rich in tri-calcium aluminate. Cem Concr Res 26(5): 717-727. https://doi.org/10.1016/s0008-8846(96)85009-5

32. Birnin-Yauri UA, Glasser FP (1998) Friedel's salt, $\mathrm{Ca}_{2} \mathrm{Al}(\mathrm{OH})_{6}(\mathrm{Cl}, \mathrm{OH}) \cdot 2 \mathrm{H}_{2} \mathrm{O}$ : its solid solutions and their role in chloride binding. Cem Concr Res 28(12): 1713-1723. https://doi.org/10.1016/S0008-8846(98)00162-8

33. Qiao C, Suraneni P, Then NWY, Choudhary A, Weiss J (2019) Chloride binding of cement pastes with fly ash exposed to $\mathrm{CaCl}_{2}$ solutions at 5 and $23^{\circ} \mathrm{C}$. Cem Concr Compos 97:43-53. https://doi.org/10.1016/j. cemconcomp.2018.12.011

34. Famy C, Scrivener KL, Atkinson A, Brough AR (2001) Influence of the storage conditions on the dimensional changes of heat-cured mortars. Cem Concr Res 31(5):795-803. https://doi.org/10.1016/S0008-8846(01)00480-X

35. Galan I, Perron L, Glasser FP (2015) Impact of chloride-rich environments on cement paste mineralogy. Cem Concr Res 68:174-183. https://doi.org/10.1 016/j.cemconres.2014.10.017

36. Arganda-Carreras I, Kaynig V, Rueden C, Eliceiri KW, Schindelin J, Cardona A, Sebastian Seung H (2017) Trainable Weka Segmentation: a machine learning tool for microscopy pixel classification. Bioinformatics 33(15):24242426. https://doi.org/10.1093/bioinformatics/btx180

37. Liao W, Sun X, Kumar A, Sun H, Ma H (2019) Hydration of binary portland cement blends containing silica fume: a decoupling method to estimate degrees of hydration and pozzolanic reaction. Front Mater 6(78). https://doi. org/10.3389/fmats.2019.00078

\section{Publisher's Note}

Springer Nature remains neutral with regard to jurisdictional claims in published maps and institutional affiliations.

\section{Submit your manuscript to a SpringerOpen ${ }^{\circ}$ journal and benefit from:}

- Convenient online submission

- Rigorous peer review

- Open access: articles freely available online

- High visibility within the field

- Retaining the copyright to your article

Submit your next manuscript at $>$ springeropen.com 